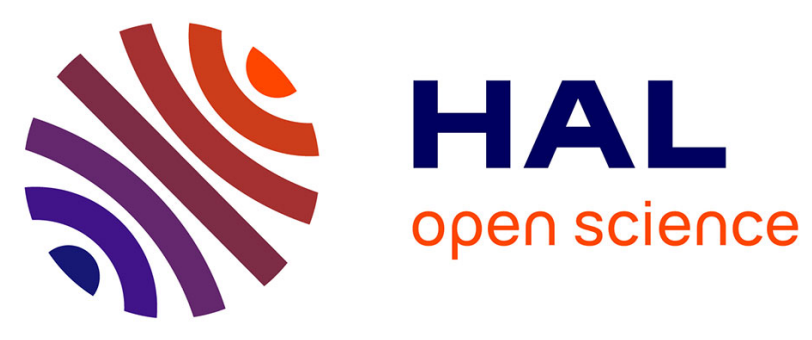

\title{
Using food comfortability to compare food's sensory characteristics expectations of elderly people with or without oral health problems
}

Mathilde Vandenberghe-Descamps, Claire Sulmont-Rossé, Chantal Septier, Gilles Feron, Hélène Labouré

\section{To cite this version:}

Mathilde Vandenberghe-Descamps, Claire Sulmont-Rossé, Chantal Septier, Gilles Feron, Hélène Labouré. Using food comfortability to compare food's sensory characteristics expectations of elderly people with or without oral health problems. Journal of Texture Studies, 2017, 48 (4), pp.280-287. 10.1111/jtxs.12250 . hal-02142337

\section{HAL Id: hal-02142337 \\ https://institut-agro-dijon.hal.science/hal-02142337}

Submitted on 18 Feb 2021

HAL is a multi-disciplinary open access archive for the deposit and dissemination of scientific research documents, whether they are published or not. The documents may come from teaching and research institutions in France or abroad, or from public or private research centers.
L'archive ouverte pluridisciplinaire HAL, est destinée au dépôt et à la diffusion de documents scientifiques de niveau recherche, publiés ou non, émanant des établissements d'enseignement et de recherche français ou étrangers, des laboratoires publics ou privés. 


\title{
Using food comfortability to compare food's sensory characteristics expectations of elderly people with or without oral health problems
}

Authors: Mathilde Vandenberghe-Descamps ${ }^{\mathrm{a}}$, Claire Sulmont-Rosséa ${ }^{\text {, Chantal Septier }}{ }^{\mathrm{a}}$, Gilles Feron ${ }^{\mathrm{a}}$, Hélène Labouré ${ }^{\mathrm{a}}$

${ }^{\text {a }}$ Centre des Sciences du Goût et de l'Alimentation, AgroSup Dijon, CNRS, INRA, Univ. Bourgogne Franche-Comté, F-21000 Dijon, France.

Short manuscript title: Food comfortability assessment and oral health problems in elderly people

Keywords: elderly, older adults, food comfortability, texture, orosensory perception

\begin{abstract}
Food consumption is by far the most important point where food's organoleptic properties can be perceived and can elicit sensory pleasure. Ageing is often accompanied by oral impairments. Those impairments may impact food perception by changing texture perception and the release of flavour components, which have a significant impact on food acceptability. The present study aimed at evaluating the impact of oral health on the perception of food comfortability in an elderly population. This was achieved by asking elderly people with a good oral health and elderly people with poor oral health to rate six cereal products and six meat products using a food comfortability questionnaire. Thirty-seven and 35 elderly people (65-87 years old) underwent either a cereal or meat session, respectively. The present study showed very few effects of dental and saliva status on food perception. For the cereal products, a significant effect of dental status was observed for one texture descriptor and one flavour descriptor, and a significant effect of salivary status was observed for two texture
\end{abstract}


descriptors and one flavour descriptor. For the meat products, a significant effect of dental status and a significant effect of salivary status were observed on one flavour descriptor. For both products, no significant impact of dental or salivary status was observed on the general perception of food oral comfort nor on food bolus formation. Future studies exploring the impact of a broader set of oral parameters and potential adapting factors are needed to further explore the results of the present study.

\section{Practical applications}

During oral food consumption, mastication, salivation and swallowing play a key role in the acceptance of food and beverages by modulating the perception of texture, taste and aroma, as well as providing eating comfort by assisting the food breakdown process into a bolus that can be safely swallowed. The age-related oral impairments such as loss of teeth, decrease in salivary flow or dysphagia are known to have an impact on food consumption. However, very few products are developed to skirt those impairments. Therefore, in the context of an ageing population, there is a need to develop functional foods that meet the specific nutritional needs of the elderly population, as well as a well-balanced flavour and texture framework. Considering the large inter-individual variability observed on the elderly people, developing adapted functional foods is a major challenge for the food industry and society.

\section{INTRODUCTION}

When a food is put in the mouth, oral processes, namely, mastication, salivation and swallowing, play a key role in texture and flavour perception, which have a significant impact on food acceptability (Yven et al., 2006). As ageing is often accompanied by oral impairments, it is often assumed that age-related changes in oral health may therefore impact 
food perception by changing texture perception (Mioche et al., 2002) (Veyrune and Mioche, 2000) and the release of flavour components (Duffy et al., 1999)

First, each tooth is connected to periodontal mechanoreceptors (up to 2000 mechanoreceptors per tooth) that signal information about tooth loads in a temporal, spatial and intensive aspect. Those mechanoreceptors are located in the ligaments that attach the tooth root to the alveolar bone, among the collagen fibres (Trulsson, 2006). When teeth are extracted, the remnants of the periodontal ligament break down. According to data from animal studies, this leads to changes in the neuro-muscular pattern and in periodontal sensitivity (Veyrune and Mioche, 2000); (Braud and Boucher, 2015). For instance, a study in cats has shown that after teeth extraction, the periodontal mechanoreceptor neurones no longer responded to mechanic stimulation (Linden and Scott, 1989). Those observations are also done in humans, and Devezeaux de Lavergne et al. (2015) highlighted the fact that passive tactile sensitivity depends largely on the presence of the periodontal ligament receptors. Indeed, in a denture wearing elderly population, the texture perception is altered compared to an elderly population with natural dentition (Mojet et al., 2005). Consequently, it may be assumed that age-related tooth loss could have an impact on periodontal sensitivity and thus on texture perception in the elderly population. Second, ageing is also often accompanied by a decrease in muscle strength (Fontijn-Tekamp et al., 2004). It has been demonstrated that reduced strength in the jaw masticatory muscles and an alteration of dental status can have an impact on biting and chewing behaviour (Mioche et al., 2004). It may be assumed that these changes could have an impact on the perception of food rheological properties such as tenderness, elasticity, firmness, and melting, among others. Third, ageing may often be accompanied by a decrease in salivary flow (Vandenberghe-Descamps et al., 2016) or changes in salivary composition (Vissink et al., 1996), which in turn may have an impact on taste and texture perception. Indeed, it may be considered that an age-related decrease in salivary flow could 
modulate the perception of oral sensations such as viscosity, smoothness, juiciness, and astringency, among others (Neyraud, 2014). Furthermore, Engelen et al. (2007) demonstrated that subjects with high $\alpha$-amylase activity had a decreased thickness perception of starchbased custard. Finally, mastication and saliva transform a food sample into a bolus that can be safely swallowed (Prinz and Lucas, 1997) (Shaw and Martino, 2013). These food breakdown processes also lead to the release of chemical compounds responsible for taste and aroma perception. Age-related impairments have been demonstrated to have a significant impact on food bolus formation (Bessadet et al., 2013); (Veyrune and Mioche, 2000). For instance, Bessadet et al. (2013) showed that denture wearers presented a decrease in the median particle size of food boluses in comparison to elderly people without removable denture prosthesis. In parallel, it may also be hypothesized that a decrease in food breakdown efficiency could lead to changes in flavour release.

In a recent study, we have explored the concept of "oral comfort" when eating a food in the elderly population (Vandenberghe-Descamps et al., in prep.). Three focus groups were conducted with elderly people. Each group included volunteers with poor oral health and volunteers with good oral health, in regards to dental status and salivary flow rate. The results of the focus groups, which included brainstorming (What is oral comfort for you?) and food tasting, revealed four dimensions underlying the concept of "oral comfort": the ability to form a food bolus, pain perception, texture perception, and flavour perception. The results were used to create a "food comfortability" questionnaire that included items on these four dimensions. This questionnaire was used in the present study to evaluate the impact of oral health status on food perception in elderly participants. Among the three identified oral health parameters (i.e., salivary status, dental health and muscle strength), the first two were studied in the present experiment. Specifically, we asked elderly people with a good oral health and 
elderly people with poor oral health (poor dental status and/or low salivary flow) to rate six cereal products and six meat products using the food comfortability questionnaire.

\section{MATERIALS AND METHODS}

\section{Participants}

The data were collected as part of a programme that aimed at studying the relationship between oral health and eating behaviour (AlimaSSenS project: towards an adapted and healthy food supply for elderly people). Among the 50 AlimaSSenS project's volunteers recruited at that time, 37 and 34 subjects were available for the cereal-based products and the meat-based products sessions, respectively. The recruitment criteria were as follows: older than 65 years old, living at home, no acute pathological episodes neither at the time of the experiment nor in the recent past, a score of at least 24 on the mini mental state evaluation (MMSE) (Folstein et al., 1975), and a number of functional units equal to 7 or more (for nonoral health problems) and equal to 4 or less (for oral health problems). The thresholds of 7 and 4 functional units to define good and bad dental status, respectively, were defined according to Leake et al. (1994). A functional unit was defined as a pair of posterior antagonist teeth that had at least one contact area during chewing. An interview and a dental examination were carried out with each volunteer to ensure that they met the inclusion criteria. In parallel, the resting salivary flow of every volunteer was measured by instructing the participant to spit out the saliva into a pre-weighed screw-cap cup every time they felt like swallowing over a period of $10 \mathrm{~min}$. Salivary flow rate was expressed in $\mathrm{ml} / \mathrm{min}$, assuming that $1 \mathrm{~g}$ of saliva corresponds to $1 \mathrm{ml}$. As with the number of functional units, the participants were categorized into two groups depending on their salivary flow. The cut-off value corresponds to the median resting salivary flow observed in 180 AlimaSSenS project's volunteers (65-92 years-old) and is equal to $0.26 \mathrm{ml} / \mathrm{min}$. Therefore, elderly people with a salivary flow below $0.26 \mathrm{ml} / \mathrm{min}$ 
were considered as having a low salivary flow, and elderly people with a salivary flow over $0.26 \mathrm{ml} / \mathrm{min}$ were considered as having a high salivary flow.

\section{Products}

Six cereal-based products and six meat-based products were chosen in order to have contrasted textures. The cereal-based products included a crispbread, a financier, a madeleine, a sponge cake, a milk roll and a protein enriched milk roll. The meat-based products included stewed cheek, beefsteak, ground beef, chicken meatballs, chicken aiguillette and ground chicken reconstituted in an aiguillette shape.

\section{Procedure}

The volunteers were invited to take part in one session where they had to taste 6 products, either the cereal-based products or the meat-based products. For each product, the volunteers were asked to answer the "food comfortability" questionnaire (Figure 1). At the beginning of each session, the questionnaire was presented to the volunteers by the experimenter. No specific training was performed before the sessions. The questionnaire included five sections (Vandenberghe-Descamps et al., in prep.).

- A first general question on food comfort that the participants answered using a 5-point scale ranging from "Very uncomfortable" to "Very comfortable."

- A second section on bolus formation included five items: the ability to cut the food with incisors, the ability to cut the food with premolars, the ability to masticate the food, the ability to humidify the food with saliva, and the ability to swallow the food. For each item, participants answered on 6-point scale ranging from "Impossible" to "Very easy." This section also included an item on the time needed to form the food bolus; participants answered using a 6-point scale ranging from "Impossible" to "Very brief." 
- A third section on pain perception included five items: burning or spicy sensation, muscular pain, articular pain, dental pain and gum pain. For each item, participants answered on a 4-point scale ranging from "Extremely" to "Not at all."

- A fourth section on texture perception included eight items that were evaluated on their intensity: sticky, stringy, greasy, dry, doughy, melting, firm and hard. The items were rated on a 4-point scale ranging from "Extremely" to "Not at all."

- A fifth section on flavour perception included five items: taste intensity and the salty, sugary, acidic and bitter perceptions. For each item, participants answered on a 4-point scale ranging from "Extremely" to "Not at all."

\section{Figure 1 about here}

During the sessions, the volunteers were free to bite the products as many times as they wanted in order to answer the questions on the "food comfortability" questionnaire. The participants were given a 3-min rest time between samples, and they were free to drink as much water as they needed during the session. Meat-based products were cooked right before serving according to the recipes provided by the supplier. They were served when the temperature in the heart of the product reached at least $+65^{\circ} \mathrm{C}$. The sessions were conducted in a sensory room equipped with individual booths according to the AFNOR standard (AFNOR, 1987) and under white light. The room temperature was $20.5 \pm 0.5^{\circ} \mathrm{C}$. The products were presented in an order determined by a William Latin square design; they were coded with a three digit number.

\section{Data analysis}

Separate analyses were conducted for the cereal products and for the meat products. For each item of the "food comfortability" questionnaire, scores were submitted to an analysis of variance (ANOVA) with three fixed factors (i.e., product, dental status (poor or good), 
salivary status (low or high)) and one random factor (participant). Post hoc comparisons were performed using the Student Newman Keuls test. Means (M) were associated with their standard errors (SEM). The threshold for significance was set at 5\%. Statistical analyses were conducted using R-studio software version 3.3.1 with the "nlme" package for linear mixed models and the "agricolae" package for post hoc analyses (R Development Core Team, 2006).

\section{RESULTS}

\section{Panel description}

The general characteristics of participants recruited from the cereal testing and the meat testing are described in Table 1. Regarding dental status, we distinguished elderly people with good dental status ( 7 or more functional units) from elderly people with poor dental status (4 or less functional units, possibly wearing denture). For both product categories the number of functional units of the elderly participants in the poor dental status group was significantly lower than that of the elderly participants in the good dental status group (cereal-based products: $\mathrm{t}(36)=13.17 ; \mathrm{P}<0.001$; meat-based products: $\mathrm{t}(33)=13.04 ; \mathrm{P}<0.001)$. Regarding salivary status, we distinguished elderly people with a high salivary flow (higher than 0.26 $\mathrm{ml} / \mathrm{min}$ ) from elderly people with a low salivary flow (lower than $0.26 \mathrm{ml} / \mathrm{min}$ ). The salivary flow of the elderly participants in the low salivary flow group was significantly lower than that of the elderly participants in the high salivary flow group (cereal-based products: $\mathrm{t}(36)=10.13 ; \mathrm{P}<0.001$; meat-based products: $\mathrm{t}(33)=10.54 ; \mathrm{P}<0.001)$.

\section{Table 1 about here}

\section{Results on cereal-based products}

The results on the dentition effect reveal that there was no effect of dental status on the general question of food comfortability (Table 2). Few effects were observed in the sub- 
dimensions of food comfortability. A significant dentition effect was observed on muscle pain and dental pain. Elderly people with a poor dentition reported feeling more muscle and dental pain while eating the food than elderly people with a good dentition. A dentition effect was also observed on the perception of a stringy texture. Elderly people with a poor dentition found the cereal-based products less stringy than elderly people with a good dentition.

The results on the saliva effect reveal that there was no effect of salivary status on the general question of food comfortability (Table 2). A significant salivary effect was observed on muscle and dental pain and on the stringiness and hardness of the food. The results showed that elderly people with a low salivary flow felt more muscle and dental pain and found the cereal-based products harder but less stringy than elderly people with a high salivary flow.

Moreover, a significant dental status $\times$ saliva status interaction was observed for muscle pain, articular pain, dental pain, greasiness and acidic items; the volunteers with poor dental status and a low salivary flow found that eating the products resulted in more muscle, articular and dental pain and considered the products less greasy but more acidic than the other groups.

\section{Results on meat-based products}

The results on the dentition effect reveal that there was no effect of dental status on the general question of food comfortability (Table 2). Few effects were observed in the subdimensions of food comfortability. A significant dentition effect is observed on muscle pain. Elderly people with a poor dentition reported feeling more muscle pain during food consumption than elderly people with a good dentition. A dentition effect was also observed on the acidic perception. Elderly people with a poor dentition found the products more acidic than elderly people with a good dentition. 
The results on saliva effect reveal that there was no effect of salivary status on the general question of food comfortability (Table 2). A significant effect was observed on the perception of sweetness. Elderly people with a poor dentition found the products less sweet than elderly people with a good dentition.

Moreover, a significant dental status $\times$ saliva status interaction was observed for the burning sensation; the elderly people with a poor dentition and a low salivary flow felt more burning sensations while eating than the other groups.

\section{Table 2 about here}

\section{DISCUSSION}

Contrary to what was expected, we observed only few effects of dental or salivary status on cereal and meat products perception. For the cereal products, poor oral status induced slightly more muscular and dental pain. However, a significant effect of dental status was observed for only one texture descriptor and one flavour descriptor, and a significant effect of salivary status was observed for only two texture descriptors. A significant effect of the interaction saliva $\times$ dental status was also observed on three pain descriptors and one flavour descriptor. For the meat-based products, poor oral status induced slightly more muscular pain. A significant effect of dental status and a significant effect of salivary status were observed on one flavour descriptor. No significant impact of dental or salivary status was observed on the general perception of food oral comfort nor on food bolus formation.

Several methodological limitations can be initially considered to explain these inconclusive results.

First, the number of volunteers was relatively small. Therefore, the results need to be carefully considered, in particular those on saliva-dental status interaction, and studies with a higher 
number of volunteers are recommended. However, it is challenging to recruit elderly people with poor oral health at a good cognitive level to carry out the sensory tests. In fact, elderly people with poor oral health are usually frail and dependent, and therefore, they are less willing to take part in this type of study (Maître et al., 2015).

Second, the recruited volunteers were naive in terms of sensory analysis and were therefore not used to rating food on sensory descriptors. Their inexperience might have led to a misunderstanding of the items and/or the misusing of the scales. These points were evaluated during the creation of the food comfortability questionnaire (Vandenberghe-Descamps et al., in prep.). To check rating repeatability, participants from the cereal panel were invited to come back to the laboratory three months later for a second session. During this session, they were asked to rate the same cereal products using the same "food comfortability" questionnaire under similar experimental conditions. The data from the first and the second session were submitted to an ANOVA with product and session as fixed factors. The results showed a significant session effect for five descriptors: ability to masticate the food, ability to swallow the food, stringy, greasy, and doughy. For all these descriptors, participants gave higher scores during the first session than during the second one. However, a significant product $\times$ session interaction was observed for only the descriptor doughy; the financier belonged to the 'doughy' products in the first session (with the madeleine, the milk roll and the protein-enriched milk roll), while it belonged to the "not doughy" products in the second session (with the crispbread). None of the other questionnaire items were associated with a significant product $\times$ session interaction, providing that the participants were quite repeatable when scoring the products for food comfortability.

Third, only two oral health parameters were used in the present study for assessing the oral status of the participant: the number of functional units and the resting salivary flow. Indeed, the number of functional units is known to be a key determinant of masticatory performance 
(Hatch et al., 2001), and the resting salivary flow reflects an individual's basic physiological status rather than his/her immediate reflex response to stimulation. However, other oral parameters could have been taken into account. Regarding mastication, muscle mass and bite force are known to decrease with age and thus decrease masticatory performance (Hatch et al., 2001); (Woda et al., 2006). However, Kohyama et al. (2003) demonstrated that elderly people cope relatively well with muscular weakness by extending the time cycle of mastication. Regarding salivation, previous studies have concluded that a value of $0.1 \mathrm{ml} / \mathrm{min}$ defines hyposalivation. However, most of these studies were conducted with frail, dependent and highly medicated elderly people (Muñoz-González et al., in prep.). In the present study conducted with healthy elderly people living at home, only $6 \%$ of the participants displayed a resting salivary flow below $0.1 \mathrm{ml} / \mathrm{min}$. Furthermore, the present study compared elderly people with low salivary flow versus high salivary flow, not necessarily elderly people with hyposalivation versus elderly without hyposalivation. Indeed, a person with hyposalivation can be defined as having a resting salivary flow rate below $0.1 \mathrm{ml} / \mathrm{min}$; meanwhile, we limited our subjects having a resting salivary flow that was based on the median resting salivary flow observed in a large sample of healthy and autonomous elderly people (i.e., AlimaSSenS sample, $\mathrm{n}=180$ ). Furthermore, it could be argued that measuring stimulated salivary flow rather than resting salivary flow would be better representative of the saliva flow induced by the consumption of a food. Measuring stimulated salivary flow consists in collecting saliva either during a mechanical stimulation (chewing a piece of paraffin wax during collection) or a gustatory stimulation (application of citric acid on the anterior surface of the tongue). However, those two stimulations are a reduced representation of stimulated saliva during food eating, which involves a much more complex stimulation (Ekström et al., 2012). Indeed, it has been shown in cereal products (toast and cake) that stimulated salivary flow during food consumption is significantly higher than mechanically stimulated salivary flow (Gavião et al., 
2004) Moreover, the authors observed a significant correlation between resting salivary flow and food-stimulated salivary flow, which suggested that resting salivary flow can be an indicator of the amount of saliva secreted during eating. Furthermore, the measure of stimulated salivary flow was associated with a large variability, whether between the different stimulations or even inside one stimulation but with different methods to collect saliva (Navazesh and Christensen, 1982).

To the best of our knowledge, the present experiment is the very first one that studied the impact of dental status and salivary flow on food perception, particularly texture and taste perception, in the elderly population. However, the absence of conclusive results observed in the present study is consistent with the results of the very few studies that investigated texture perception in older people. In fact, the research studies on meat texture produced by Mioche and collaborators showed no aged-related effects in terms of tenderness and juiciness perception when comparing young subjects and old adults with good dental health (Mioche, 2004). Veyrune and Mioche (2000) noticed that subjects with complete dentures were more sensitive to changes in juiciness of meat samples compared to dentate subjects, but the toughness perception of meat was similar between the two groups. Several hypotheses can be proposed to explain this lack of strong impact of age-related oral impairment on texture perception.

First, it may be assumed that the few remaining teeth of the elderly people with poor dental status are sufficient to discriminate the products, in particular, products that present large differences in terms of texture and/or flavour, as was the case in the present experiment. In fact, texture perception does not exclusively rely on periodontal mechanoreceptors. There are also mechanoreceptors in the other oral mucosa (tongue, palate, cheek) which may be sufficient to perceive food texture when the periodontal sensitivity is impaired due to tooth loss. Second, it is also possible that low saliva flow subjects had low saliva flow for a long 
time or that saliva flow had decreased progressively in time. In this case, they do not realize that it takes them longer to humidify the food with their saliva, and do not consider the food drier than elderly people with a high salivary flow. They probably adapted their food oral processing to this low saliva flow without any consequence in dry perception and food comfortability. Third, elderly people with poor oral health may have adapted their eating behaviour, such as mouthful size, chewing time or the amount of water drunk. Regarding mouthful size, Goto et al. (2015) suggested that a decrease in the mouthful size might assist with the formation of a bolus to cope with poor oral health. In the present experiment, we measured spontaneous mouthfuls of the cereal products during the second session that was organized to measure rating repeatability. For each product, five samples were served to the participants. Participants were asked to bite one time in each sample, and mouthful sizes were weighted by the experimenters. The results showed no difference between participants, whether they had oral impairments (poor dental status or low salivary flow rate) or not. They did not adapt the size of their mouthful according to their oral health. Regarding chewing time, it may be assumed that elderly people with oral impairment spend more time chewing food, particularly uncomfortable food, but they would not consciously realize it as it resulted from a progressive decline in oral health. The chewing time should be measured in further studies in order to confirm or infirm this hypothesis. Regarding the amount of water drunk, Shiozawa and Kohyama (2011) demonstrated that the addition of water in the mouth during mastication would facilitate the formation of a food bolus suitable for swallowing, regardless of the type of food. It may be assumed that elderly people with a low salivary flow drink a larger amount of water during food consumption. Measuring the amount of water drunk during the sessions in future studies will help in better understanding the eating behaviour of this specific population. 


\section{CONCLUSION}

In conclusion, we observed very few effects of dental and saliva status on food perception for cereal-based and meat-based products. This is consistent with the results of the very few studies that investigated texture perception in older people. However, before drawing definitive conclusions, future studies should explore the impact of a broader set of oral parameters including muscle strength and measure potential adapting factors (mouthful size, chewing time, and water drunk...). Furthermore, it could be interesting to consider the impact of age-related impairment on the perception of food products, which displayed a smaller sensory difference than in the present experiment.

\section{Ethical Statements}

The authors declare that they do not have any conflicts of interest. The experimental protocol was approved by the French Ethics Committee for Research (CPP Est III, Nancy, \#15.04.04, ANSM \#2015-A00279-40). In accordance with ethical standards, all participants received written and oral information on the study before signing a consent form.

\section{Acknowledgements}

This study is part of AlimaSSenS [ANR-14-CE20-0003-01] funded by the French National Research Agency. This work was also supported by grants from the Regional Council of Burgundy France and the European Funding for Regional Economic Development (FEDER). The authors thank Laura Halupka (Cerelab) and Marine Michel (Terrena Innovation) for the work they did on the recipes and their advice on the chosen products, Françoise Durey (ChemoSens Platform) for her technical support, and Laurine Saulier, Martine Hennequin and Marie-Agnès Peyron for their help and advice on the characterization of oral health (Laboratoire de Physiologie Orofaciale, Université d'Auvergne). 


\section{References}

BESSADET, M., NICOLAS, E., SOCHAT, M., HENNEQUIN, M., and VEYRUNE, J.L. 2013. Impact of removable partial denture prosthesis on chewing efficiency. Journal of applied oral science : revista FOB 21, 392-396.

DEVEZEAUX DE LAVERGNE, M., DERKS, J.A.M., KETEL, E.C., DE WIJK, R.A., and STIEGER, M. 2015. Eating behaviour explains differences between individuals in dynamic texture perception of sausages. Food Quality and Preference 41, 189-200.

DUFFY, V.B., CAIN, W.S., and FERRIS, A.M. 1999. Measurement of Sensitivity to Olfactory Flavor: Application in a Study of Aging and Dentures. Chemical Senses 24, 671-677.

EKSTRÖM, J., KHOSRAVANI, N., CASTAGNOLA, M., and MESSANA, I. 2012. Saliva and the Control of Its Secretion. In Dysphagia: Diagnosis and Treatment. O. Ekberg, ed. Springer Berlin Heidelberg, Berlin, Heidelberg pp. 19-47.

ENGELEN, L., VAN DEN KEYBUS, P.A., DE WIJK, R.A., VEERMAN, E.C., AMERONGEN, A.V., BOSMAN, F., PRINZ, J.F., and VAN DER BILT, A. 2007. The effect of saliva composition on texture perception of semi-solids. Arch Oral Biol 52, 518-525.

FOLSTEIN, M.F., FOLSTEIN, S.E., and MCHUGH, P.R. 1975. "Mini-mental state". A practical method for grading the cognitive state of patients for the clinician. $\mathrm{J}$ Psychiatr Res 12, 189-198.

FONTIJN-TEKAMP, F.A., VAN DER BILT, A., ABBINK, J.H., and BOSMAN, F. 2004. Swallowing threshold and masticatory performance in dentate adults. Physiology \& Behavior 83, 431-436.

GAVIÃO, M.B., ENGELEN, L., and VAN DER BILT, A. 2004. Chewing behavior and salivary secretion. European Journal of Oral Sciences 112, 19-24.

GOTO, T., NAKAMICH, A., WATANABE, M., NAGAO, K., MATSUYAMA, M., and ICHIKAWA, T. 2015. Influence of food volume per mouthful on chewing and bolus properties. Physiol Behav 141, 58-62.

HATCH, J.P., SHINKAI, R.S., SAKAI, S., RUGH, J.D., and PAUNOVICH, E.D. 2001. Determinants of masticatory performance in dentate adults. Archives of Oral Biology 46, 641-648.

KOHYAMA, K., MIOCHE, L., and BOURDIOL, P. 2003. Influence of age and dental status on chewing behaviour studied by EMG recordings during consumption of various food samples. Gerodontology 20, 15-23.

LEAKE, J.L., HAWKINS, R., and LOCKER, D. 1994. Social and functional impact of reduced posterior dental units in older adults. J Oral Rehabil 21, 1-10.

LINDEN, R.W.A., and SCOTT, B.J.J. 1989. The effect of tooth extraction on periodontal ligament mechanoreceptors represented in the mesencephalic nucleus of the cat. Archives of Oral Biology 34, 937-941.

MIOCHE, L. 2004. Mastication and food texture perception: Variation with age. Journal of Texture Studies 35, 145-158.

MIOCHE, L., BOURDIOL, P., MONIER, S., and MARTIN, J.F. 2002. The relationship between chewing activity and food bolus properties obtained from different meat textures. Food Quality and Preference 13, 583-588.

MIOCHE, L., BOURDIOL, P., and PEYRON, M.A. 2004. Influence of age on mastication: effects on eating behaviour. Nutrition Research Reviews 17, 43-54.

MOJET, J., CHRIST-HAZELHOF, E., and HEIDEMA, J. 2005. Taste perception with age: pleasantness and its relationships with threshold sensitivity and supra-threshold intensity of five taste qualities. Food Quality and Preference 16, 413-423. 
MUÑOZ-GONZÁLEZ, C., VANDENBERGHE-DESCAMPS, M., FERON, G., CANON, F., LABOURÉ, H., and SULMONT-ROSSÉ, C. in prep. Does salivary hypofunction affect food consumption in the elderlies? A Systematic Literature Review. Physiology \& Behavior.

NAVAZESH, M., and CHRISTENSEN, C.M. 1982. A Comparison of Whole Mouth Resting and Stimulated Salivary Measurement Procedures. Journal of Dental Research 61, 1158-1162.

NEYRAUD, E. 2014. Role of saliva in oral food perception. Monogr Oral Sci 24, 61-70.

PRINZ, J.F., and LUCAS, P.W. 1997. An optimization model for mastication and swallowing in mammals. Proc Biol Sci 264, 1715-1721.

SHAW, S.M., and MARTINO, R. 2013. The normal swallow: muscular and neurophysiological control. Otolaryngologic clinics of North America 46, 937-956.

SHIOZAWA, K., and KOHYAMA, K. 2011. Effects of Addition of Water on Masticatory Behavior and the Mechanical Properties of the Food Bolus. Journal of Oral Biosciences 53, 148-157.

TRULSSON, M. 2006. Sensory-motor function of human periodontal mechanoreceptors. J Oral Rehabil 33, 262-273.

VANDENBERGHE-DESCAMPS, M., LABOURÉ, H., PROT, A., SEPTIER, C., TOURNIER, C., FERON, G., and SULMONT-ROSSÉ, C. 2016. Salivary Flow Decreases in Healthy Elderly People Independently of Dental Status and Drug Intake. Journal of Texture Studies 47, 353-360.

VANDENBERGHE-DESCAMPS, M., SULMONT-ROSSÉ, C., SEPTIER, C., FERON, G., and LABOURÉ, H. in prep. Food comfortability: a new concept to understand elderlies' expectations in terms of sensory characteristics. Food Quality and Preference.

VEYRUNE, J.L., and MIOCHE, L. 2000. Complete denture wearers: electromyography of mastication and texture perception whilst eating meat. Eur J Oral Sci 108, 83-92.

VISSINK, A., SPIJKERVET, F.K.L., and AMERONGEN, A.V.N. 1996. Aging and saliva: A review of the literature. Special care in Dentistry 16.

WODA, A., MISHELLANY, A., and PEYRON, M.A. 2006. The regulation of masticatory function and food bolus formation. J Oral Rehabil 33, 840-849.

YVEN, C., BONNET, L., CORMIER, D., MONIER, S., and MIOCHE, L. 2006. Impaired mastication modifies the dynamics of bolus formation. Eur J Oral Sci, 184-190. 


\section{Figure 1. Food comfortability questionnaire}

\begin{tabular}{lcccc}
\hline General question & & & & \\
\hline This food is... & & & & \\
Very uncomfortable & Uncomfortable & Moderately comfortable & Comfortable & Very comfortable \\
$\square$ & $\square$ & $\square$ & $\square$ & \\
\hline Bolus formation & & & \\
\hline
\end{tabular}

To cut this food with your incisor is...

\begin{tabular}{|c|c|}
\hline Impossible & Very difficult \\
\hline & \\
\hline
\end{tabular}

Same scale for cutting with premolars, masticating, humidification with saliva, swallowing and time needed to form the food bolus

Mouth pain

Does eating the food bring a burning or spicy sensation?
Extremely
A lot
Little
Not at all
$\square$
口
口


Same scale for muscular pain, articular pain, dental pain and gum pain

\begin{tabular}{|c|c|c|c|}
\hline Texture & & & \\
\hline \multicolumn{4}{|l|}{ Is this food sticky? } \\
\hline Extremely & A lot & Little & Not at all \\
\hline$\square$ & $\square$ & $\square$ & $\square$ \\
\hline
\end{tabular}

\begin{tabular}{lccc}
\hline Flavour & & \\
\hline Is this food intense in taste? & A lot & Little & Not at all \\
Extremely & $\square$ & $\square$ & $\square$ \\
$\square$ & $\square$
\end{tabular}

Same scale for salty, sugary, acidic and bitter 
1 Table 1. General characteristics of participants

\begin{tabular}{|c|c|c|c|}
\hline & & Cereal panel & Meat panel \\
\hline \multicolumn{2}{|c|}{ Number of participants } & 37 & 34 \\
\hline \multicolumn{2}{|c|}{ Gender (\% female) } & $54.05 \%$ & $52.94 \%$ \\
\hline \multirow{2}{*}{ Age } & m (SEM) & $73.49(1.04)$ & 72.15 (1.07) \\
\hline & Range & $65-87$ years old & $65-87$ years old \\
\hline \multirow{6}{*}{ Dental status } & Good dental status & & \\
\hline & $\mathrm{n}$ & 23 & 22 \\
\hline & m (SEM) & 8.09 FU (0.53) & 8.27 FU (0.64) \\
\hline & Poor dental status & & \\
\hline & $\mathrm{n}$ & 14 & 12 \\
\hline & m (SEM) & 3.36 FU (0.69) & $2.58 \mathrm{FU}(0.84)$ \\
\hline \multirow{6}{*}{ Saliva status } & High salivary flow & & \\
\hline & $\mathrm{n}$ & 17 & 18 \\
\hline & m (SEM) & $0.53 \mathrm{ml} / \mathrm{min}(0.05)$ & $0.51 \mathrm{ml} / \mathrm{min}(0.05)$ \\
\hline & Low salivary flow & & \\
\hline & $\mathrm{n}$ & 20 & 16 \\
\hline & m (SEM) & $0.14 \mathrm{ml} / \mathrm{min}(0.05)$ & $0.16 \mathrm{ml} / \mathrm{min}(0.05)$ \\
\hline
\end{tabular}

2 FU: Functional Units

3 (SEM): Standard Error of the Mean 
1 Table 2. Results of the Anova on the dentition and saliva effect for both cereal-based and 2 meat-based products

\begin{tabular}{|c|c|c|c|c|c|c|c|}
\hline & \multirow[b]{2}{*}{ Variables } & \multicolumn{3}{|c|}{ Cereal-based products } & \multicolumn{3}{|c|}{ Meat-based products } \\
\hline & & $\begin{array}{l}\text { Dentition } \\
\text { effect }\end{array}$ & $\begin{array}{l}\text { Saliva } \\
\text { effect }\end{array}$ & Interaction & $\begin{array}{l}\text { Dentition } \\
\text { effect }\end{array}$ & $\begin{array}{l}\text { Saliva } \\
\text { effect }\end{array}$ & Interaction \\
\hline $\begin{array}{l}\text { General } \\
\text { perception }\end{array}$ & Comfort & 0.490 & 0.856 & 0.641 & 0.569 & 0.872 & 0.815 \\
\hline \multirow{6}{*}{$\begin{array}{l}\text { Bolus } \\
\text { formation }\end{array}$} & Incisor & 0.894 & 0.379 & 0.716 & 0.270 & 0.949 & 0.840 \\
\hline & Molar & 0.279 & 0.130 & 0.704 & 0.358 & 0.899 & 0.961 \\
\hline & Masticate & 0.656 & 0.675 & 0.545 & 0.866 & 0.812 & 0.424 \\
\hline & Humidify & 0.831 & 0.609 & 0.948 & 0.938 & 0.334 & 0.479 \\
\hline & Swallow & 0.794 & 0.228 & 0.878 & 0.685 & 0.475 & 0.406 \\
\hline & Time & 0.425 & 0.419 & 0.749 & 0.944 & 0.100 & 0.757 \\
\hline \multirow{5}{*}{ Pain } & Burn & 0.354 & 0.610 & 0.224 & 0.165 & 0.278 & $0.001^{* * *}$ \\
\hline & Muscle & $0.015^{*}$ & $0.053^{*}$ & $0.013^{*}$ & $0.012^{*}$ & 0.280 & 0.105 \\
\hline & Articular & 0.134 & 0.680 & $0.038^{*}$ & 0.607 & 0.709 & 0.175 \\
\hline & Dental & $0.012^{*}$ & $0.046^{*}$ & $0.006^{* *}$ & 0.343 & 0.716 & 0.834 \\
\hline & Gum & 0.565 & 0.150 & 0.916 & 0.839 & 0.797 & 0.416 \\
\hline \multirow{8}{*}{ Texture } & Sticky & 0.095 & 0.192 & 0.059 & 0.143 & 0.121 & 0.931 \\
\hline & Stringy & $0.045^{\star}$ & $0.048^{*}$ & 0.206 & 0.766 & 0.707 & 0.828 \\
\hline & Greasy & 0.603 & 0.609 & $0.052^{*}$ & 0.204 & 0.277 & 0.585 \\
\hline & Dry & 0.341 & 0.469 & 0.711 & 0.603 & 0.714 & 0.901 \\
\hline & Doughy & 0.793 & 0.106 & 0.101 & 0.300 & 0.306 & 0.531 \\
\hline & Melting & 0.391 & 0.206 & 0.660 & 0.730 & 0.474 & 0.540 \\
\hline & Firm & 0.312 & 0.945 & 0.208 & 0.236 & 0.528 & 0.300 \\
\hline & Hard & 0.784 & $0.046^{*}$ & 0.443 & 0.949 & 0.159 & 0.928 \\
\hline \multirow{5}{*}{ Flavour } & $\begin{array}{l}\text { Taste } \\
\text { intense }\end{array}$ & 0.547 & 0.316 & 0.565 & 0.478 & 0.876 & 0.877 \\
\hline & Salty & 0.450 & 0.870 & 0.473 & 0.338 & 0.938 & 0.340 \\
\hline & Sweet & 0.659 & 0.981 & 0.170 & 0.549 & $0.044^{*}$ & 0.464 \\
\hline & Acidic & 0.712 & 0.211 & $0.034^{*}$ & $0.016^{*}$ & 0.610 & 0.648 \\
\hline & Bitter & 0.871 & 0.313 & 0.078 & 0.455 & 0.505 & 0.805 \\
\hline
\end{tabular}

3 Presentation of the $\mathrm{p}$-value and significance levels $(* \mathrm{P}<0.05 ; * * \mathrm{P}<0.01 ; * * * \mathrm{P}<0.001)$ 